Capítulo 1.

\title{
Epistemología histórica en comunicación: la vertiente Mattelart
}

\section{DOI: https://doi.org/10.16921/ciespal.23.21}

\author{
Alberto Efendy Maldonado G. \\ CIESPAL-UNISINOS.
}

La constitución del campo de las ciencias de la comunicación en América Latina tiene como protagonistas estratégicos a Armand y Michèle Mattelart; pareja de pensadores e investigadores, de origen europeo, que asumieron el desafío radical de la desconstrucción intelectual, existencial, política y estructural, al transformarse y alfabetizarse como seres latinoamericanos, y al adoptar Nuestra América como biosfera crucial de su existencia y de su producción investigativa. Ese proceso histórico, político y científico, configuró desde inicios de la década de 1960 un compromiso ético y una competencia de conocimientos emblemáticos. Simultáneamente, y, lo que del punto de vista epistemológico es todavía más importante, la inmersión latinoamericana de la pareja Mattelart los llevó a confrontar, mezclar, deconstruir, reformular y aprender de los conocimientos y de las sabidurías indo-afro-mestizas-americanas; de hecho, se nutrieron como pocos de las sabidurías diversas de los pueblos del continente.

De modo diferente a las posturas logocéntricas y etnocéntricas, de la mayoría de especialistas e intelectuales que arriban a Nuestra América para lucrar, como reproductores del poder logocéntrico mundial, 
de sus matrices, modelos, esquemas, recetas, proyectos y estrategias; el dúo Mattelart llegó para aprender, para trabajar en igualdad de condiciones, para luchar, para existir y para amar en un contexto de compromiso con los procesos socioculturales, educativos, investigativos y constitutivos del pensamiento comunicacional crítico en el continente.

Ahora, en inicios de la tercera década del siglo XXI, cuando su trayectoria ya ha sido larga y fructífera, Armand (8/1/1936) y Michèle (22/9/1941), es posible presentar está panorámica histórica como una contribución al conocimiento, al estudio y al debate sobre esta importante vertiente crítica, que ellos han articulado para fortalecer el pensamiento crítico en ciencias de la comunicación. En ese sentido, una premisa central que cabe anotar de partida es que estamos refiriéndonos a pensamiento crítico radical emancipador en comunicación. En efecto, Michèle y Armand Mattelart, así como otros colegas que han establecido colaboraciones con ellos han construido una perspectiva epistemológica histórica para el conocimiento, la reflexión, la reconstrucción, y la rearticulación de las teorías, de las trayectorias y de las estrategias en comunicación de manera brillante. De hecho, su trabajo crítico sistemático, cuidadoso, abierto, transdisciplinar y transmetodológico, ha favorecido a los procesos de formación de investigadoras/es, pensadoras/es, comunicadoras/es y profesionales de la comunicación de manera consistente, amplia y revitalizadora.

Em la dimensión crítica, epistemológica ${ }^{1}$, cabe mencionar la obra: Pensar sobre los medios: comunicación y crítica social'2 ; en ese libro, Michèle y Armand estructuraron un análisis profundo sobre la problemática de la transdisciplinariedad, de las encrucijadas teóricas eruditas, y de las tentaciones metafóricas presentes en los quehaceres teóricos especulativos. Los autores muestran, en esas argumentaciones, la consecuente carencia epistemológica científica, de un conjunto numeroso

1 Lo que no constituye una tautología, dado que hay epistemologías conservadoras, formales, reductoras; y es importante reconocer el carácter plural de las epistemologías, en especial las autóctonas/no hegemónicas.

2 Publicada primero em francés por la Éditions La Découverte em 1986; después en español por la FUNDESCO en 1987, y en Brasil por la Loyola en 2004. 
de discursos sobre la comunicación. Problematizan, también, los paradigmas teóricos preponderantes en el contexto internacional, como la "teoría de la información" (ampliamente divulgada); y debaten sobre problemáticas teóricas cautivantes sobre la postlinearidad, el poder negociado, el retorno del sujeto, y los procedimientos de consumo. $\mathrm{Al}$ abordar las interrelaciones entre la cultura mediática y los intelectuales, argumentan sobre los desafíos de conocimiento que exigen la investigación del placer popular; la deconstrucción de dicotomías, como aquellas que clasifican lo cultural como negativo/afirmativo, o pesado/ leve. Enfrentan la especulación teórica que afirma el supuesto ocaso de los macro/sujetos (Estado, Industrias Culturales), y desmontan las propuestas globalizantes sobre el Homo Deregulatus, como una cosmo-biología del ser humano encuadrado en el modelo capitalista. Para completar esas problematizaciones, argumentan sobre la crisis de los paradigmas, la sobrevivencia de la dialéctica, y el reencuentro con lo popular; y demuestran la vigencia, relevancia, pertinencia y potencia del pensamiento crítico histórico comprometido con la transformación del mundo; a pesar de ser realizado en un ambiente intelectual de preponderancia conservadora, dado el auge del neoliberalismo, la desestructuración del socialismo real europeo y la fuerza de la tecnociencia positivista en aquella época.

La epistemología histórica que la pareja Mattelart ha brindado para el campo de estudios en comunicación se concretiza, por ejemplo, en un libro síntesis pedagógico, ampliamente trabajado en los cursos tanto de Europa como de América Latina, se trata de la Historia de las Teorías de la Comunicación ${ }^{3}$. Una obra que va a ofrecer a las y los profesores, estudiantes, profesionales, comunicadores/as e investigadores una articulación/orientación valiosa sobre la configuración histórica de las teorías de la comunicación en el siglo XX. De hecho, el libro constituye una visualización epistemológica analítica, dialéctica esclarecedora sobre las diversas vertientes, escuelas y modelos teóricos en ciencias

3 Primera edición, La Découverte, Paris, 1995; edición en español por la Paidós Ibérica, Barcelona, 1996. Edición en portugués, Campo das Letras, 1997. Primera edición en Brasil, Loyola, São Paulo, 1999. 
de la comunicación. Esta obra define una estructura diferenciada en contraposición con los manuales estructuralistas, funcionalistas e instrumentalistas; y organiza las teorías de la comunicación en siete ejes:

1. el organismo social (la configuración del modelo capitalista como base real de la mediatización);

2. los empirismos del Nuevo Mundo (la importancia de la Escuela de Chicago, y la posterior preponderancia de la mass communication research);

3. la "teoría de la información" (la versión linear/tecnicista de Shannon; y el contrapunto cibernético social de Norbert Wiener y de la Escuela de Palo Alto);

4. la Industria Cultural, la ideología y el poder (Escuela de Frankfurt, estructuralismo, Estudios Culturales);

5. la Economía Política de la comunicación (la dependencia cultural, las industrias culturales);

6. el retorno de lo cotidiano (etnometodologías; actor/sistema, la acción comunicativa, la virada lingüística, las etnografías de audiencias, los usos y gratificaciones, el consumidor/usurario; los estudios culturales feministas), y, para finalizar, el

7. la influencia de la comunicación (la figura de la red, el difusionismo, las ciencias cognitivas, el planeta híbrido y las nuevas jerarquías del saber).

Así, la vertiente Mattelart condensó y articuló problemas teóricos estratégicos para el pensamiento en comunicación, mediante exposiciones esclarecedoras, organizadoras e interrelacionares, que han contribuido, a partir de 1995, para la cualificación teórica crítica en el área.

La problemática de la constitución histórica de las condiciones de producción de la comunicación, y de los sistemas y modelos sociales mediatizados, ha sido investigada y reformulada sistemáticamente por la vertiente Mattelart; es así que, por más de cinco décadas, entre las decenas de libros importantes, que abordan esa temática, vamos 
a destacar, para empezar, Multinacionales y sistemas de comunicación, publicado por la Éditions Anthropos, Paris, $1976^{4}$; este libro fue resultado de investigaciones y estudios de campo, que hicieron posible conocer, describir y sistematizar los componentes de la guerra electrónica, los procesos mediáticos de multinacionalización, la difusión de tecnologías espaciales, las nuevas pedagogías mediatizadas (teleducación), las transformaciones en la prensa, en el cine, y el proceso crucial de marketing político, así como las transformaciones de los símbolos imperiales.

La línea epistemológica histórica constituida por la vertiente Mattelart se amplía con la producción de la obra Comunicación mundo: historia de las ideas y de las estrategias, que dio continuidad a las investigaciones realizadas sobre la estructuración de los sistemas de comunicación tecnológicos, de amplia penetración en el mundo. Esa investigación comprueba un salto dialéctico, en términos epistemológicos y teóricos, al organizar la comprensión de la dimensión comunicacional en el Sistema Mundo, de manera profunda y renovadora. Para fundamentar eso, que la obra está organizada en tres grandes partes:

1. la guerra (cinco capítulos);

2. el progreso (tres capítulos) $\mathrm{y}$,

3. la cultura (tres capítulos),

Esa estructura hizo posible articular, problematizar y comprender la dimensión comunicacional en el sistema mundo. De hecho, esas partes, que se presentan genéricas en una primera aproximación, ganan concretización y fuerza de realidad mediante los componentes de análisis establecidos. En la primera parte se aborda la problemática de las redes técnicas de comunicación; la era de las multitudes; la gestión de la gran sociedad; el choque ideológico y la escuela de la astucia; en ese conjunto, se combina una serie valiosa de informaciones, argumentos y potencias, que muestran la articulación de estrategias

4 En Brasil publicado por la L.E.C.H Librería Editora Ciencias Humanas, São Paulo, 1976. 
mediáticas y comunicacionales, en profunda interrelación con las acciones geopolíticas, militares y económicas.

En la segunda parte se problematiza el paradigma del progreso, y se combinan análisis transdisciplinares para abordar ese problema/ objeto en su diversidad política y sociológica. La comunicación emerge como una compleja aldea global, ciudad global, cerebro del planeta, e interrelaciona mitos, negocios, poderes, sociedades y universalismos subversivos. El análisis muestra, también, la capacidad sistémica de generar ilusiones de cambio y esperanzas crecientes, a partir de la teleducación, y del mercadeo de las expectativas de vida. Para cerrar esta parte, se problematiza los flujos de información y de comunicación internacional, que garantizaron la concentración de poderes mediáticos, por medio de discursos de liberalización, democratización y tecnologización.

La tercer parte de la investigación/libro Comunicación Mundo problematiza la categoría CULTURA, como un eje epistemológico estratégico para pensar y teorizar en comunicación en la cultura, se destaca las necesidades sociopolíticas de su existencia; los cambios en la participación del Estado y de los sistemas mediáticos en las configuraciones culturales; se enfatiza, como crucial, el predominio de la geoeconomía en la construcción de una cultural global (modos de gestión, estandarización, ofertas, exclusiones). Y, finalmente, se argumenta sobre la estratégica participación en los procesos comunicacionales mundiales de las mediaciones y de los mestizajes en la ofensiva de las culturas; en esa argumentación, se presentan expectativas de cambio y de transformación sociocultural renovadoras para la comunicación en el mundo.

Nuestro análisis sobre la perspectiva epistemológica histórica de la vertiente Mattelart no puede dejar de lado la obra/investigación La Invención de la Comunicación ${ }^{5}$, en ese libro se encuentra una reconstrucción histórica detallada de los procesos de instauración de

5 Obra publicada en la colección Epistemologia e sociedade, por el Instituto Piaget de Lisboa, em 1996, primera edición por la editora La Decouvert, 1994, Paris. 
los sistemas mediáticos en el mundo. La obra es organizada en cuatro partes:

1. La sociedad del flujo;

2. Las utopías del vínculo universal;

3. El espacio geopolítico y,

4. El individuo medida.

En la primera parte, problematiza los aspectos tecnofilosóficos que hicieron posible establecer una razón técnica con pretensiones universalistas; y, que, simultáneamente, orientaron a los estrategas, ingenieros y gobernantes para la construcción de los sistemas necesarios para la expansión del capitalismo. En esa parte, es problematizada también la razón estadística, la razón técnica, y las nuevas tecnologías de la comunicación y del transporte, que posibilitaron la construcción de redes ferroviarias, de redes de telégrafos, de máquinas herramientas, y de las bases e infraestructuras para la invención de los medios de comunicación de "masas".

La argumentación Mattelart se desarrolla con una combinación de las propuestas de la economía política de Adam Smith, con las contribuciones del positivismo francés (Comte) y del positivismo británico (Spencer); en ese tejido teórico, se incluye, también, la influencia decisiva del evolucionismo darwinista, las teorías y los diseños sobre la división social del trabajo mental de Babbage y Wakefield, y, la consecuente generalización de la teoría del progreso que estas fuentes teóricas alimentan.

En la segunda parte, se problematiza El Culto de la Red, y se muestra como ya en el siglo XVIII, y en el siglo XIX, la construcción de redes espirituales y de redes materiales era un eje central de transformación del mundo (redes industriales, Canal de Suez, redes ferroviarias, redes de anuncios publicitarios), todo eso como un legado del saint-simonismo positivista. En el segundo capítulo de esta parte, titulado El templo de la industria, se muestra la construcción sistemática de 
las industrias, y la consecuente transformación de las formaciones sociales, de las culturas, de los medios de comunicación, de los modos de enunciación, y de las espacialidades/temporalidades sociales. A continuación, en el tercer capítulo, se aborda la Ciudad Comunitaria, bajo ese título se argumenta y se presentan los proyectos alternativos de construcción de las sociedades, en confrontación con la lógica avasalladora del Capital; para fortalecer esta argumentación son invitados pensadores anarquistas, socialistas y comunistas utópicos, y también los [anti] utópicos. En el cuarto capítulo, se argumenta sobre la Jerarquización del Mundo, para eso se presentan los nuevos modelos de poder mundial, que la revolución técnica/industrial posibilitó. En el siguiente capítulo, titulado La propagación simbólica, se presentan argumentaciones importantes sobre las interrelaciones entre instituciones religiosas y los nuevos modos mediáticos de producción simbólica. Se muestra cómo el positivismo y los discursos eclesiásticos intervinieron en la constitución de los sistemas mediáticos. En el último capítulo, de esta tercera parte, titulado El pensamiento estratégico, se argumenta sobre los vínculos profundos entre teorías técnicas, teorías geopolíticas, teorías informacionales, teorías comunicacionales; y su participación decisiva en la instauración del sistema mundo de poder económico, político y simbólico, hegemónico capitalista.

Finalmente, en la cuarta parte del libro al problematizar El Individuo Medida, se analiza el perfil de las multitudes, para eso se convida a un conjunto importante de teóricos que fueron predecesores, y fundadores de las primeras teorías sobre los procesos sociales de transformación mediática; el aporte de la vertiente Mattelart a la historia de las teorías, en este aspecto, es de gran importancia. En esa orientación se argumenta también sobre El Motor Humano, en esos pensamientos se muestra como el conocimiento tecnocientífico se ubicó al servicio de la organización de la producción material y simbólica, para aumentar la eficiencia y la productividad en provecho del gran capital. En el capítulo final, El mercado de los objetivos (blancos), se problematiza las primeras redes publicitarias, el nacimiento del marketing; y eso se combina 
con argumentos sobre la relevancia de los géneros populares de comunicación, como el folletín; se cuestiona el ataque a las culturas de la fiesta y del ocio, concebidas en la óptica positivista como expresiones negativas para la cultura de la acumulación, de la competencia, del lucro y de la eficiencia capitalistas. En esta parte, también, se fundamenta sobre el vínculo profundo y decisivo entre culturas populares y medios de comunicación, y se muestra la diversidad de lógicas que conforman los complejos mediáticos.

La epistemología histórica de la vertiente Mattelart ofrece, entre otras importantes investigaciones, la obra titulada Historia de la utopía planetaria: de la ciudad profética a la sociedad global, publicada por primera vez en Paris por la editora La Découverte en 1999; y, en Brasil por la editora Sulina, Porto Alegre, 2002. En esa investigación histórica, se muestra, em primer lugar, como el Vínculo cristiano expandió el logocentrismo europeo, y contribuyó para instaurar el colonialismo, y el complejo sistémico capitalista en América. En la segunda parte presenta la Cosmopolis, con sus componentes de sistema de paz perpetua, de razón universal, de espíritu positivista y su invasión del mundo. En ese análisis, están incluidos temas relevantes como las humanidades socialistas precientíficas; y, reflexiona sobre los temas de la red, la técnica y el nuevo sentido del mundo, que el contexto histórico de fomento de las utopías y de realidades de expansión cultural simbólica hacía posibles. En esa concepção de Cosmopolis se muestra la función planetaria del cinematógrafo y de las redes igualitarias en la era neotécnica. Mattelart presenta las nuevas redes de interrelación en el mundo como interdependencias, y cuestiona la estrategia de "americanizar el mundo"; en esta parte, cierra sus argumentos sobre Cosmopolis con el análisis de los Estados Unidos del mundo en tiempos de guerra; realidad donde las estrategias, las lógicas, los complejos y las culturas de la guerra imperan como necesidad básica del funcionamiento sistémico capitalista hegemônico.

La investigación historia de la utopía planetaria se complementa con la argumentación sobre Tecnópolis, que comienza con una crítica 
epistemológica a la pretensión, insólita y logocéntrica, de afirmar la validez de una sola cultura y de una sola ciencia como universales; totalitarismo defendido por el modelo positivista hegemónico. En Tecnópolis se problematizan las contradicciones de ese absolutismo intelectual, que ha generado un "diálogo de sordos" entre la Europa de las Luces y la América multicultural, diversa y potente. Para fundamentar la Tecnópolis Mattelart muestra el condicionamiento internacional propuesto por el modelo de modernidad estadounidense, con su fuerza organizativa, su vigor técnico y su hegemonía simbólica; matriz sociocultural, económica y política que niega el valor y la existencia de alternativas de mundo y de vida. Mattelart desmonta la estrategia estadounidense de un planeta maniqueísta y esquizofrénico, que se encuadra en la guerra sicológica, en las confrontaciones ideológicas maximalistas entre, por ejemplo, nazistas, fascistas, estalinistas e imperialistas. Para complementar su argumentación sobre Tecnópolis, el autor analiza e interpreta la revolución gerencial, que instauró los rumbos para la nominada sociedad de la información; y la pretensión de una ciudad global sobre los principios de una religiosidad de mercadeo, y de la geopolítica militarista internacional; en esa parte, son relevantes la explicaciones sobre think globally y las acciones locales; concomitantemente, se hace una crítica del discurso milenarista de la global democratic markeplace que reduce la vida, las culturas, y las formaciones sociales a un mercado global controlado.

La perspectiva epistemológica histórica de la vertiente Mattelart generó, también, la publicación de la obra Historia de la sociedad de la información ${ }^{6}$, en esa investigación se problematiza el culto del número, uno de los aspectos preponderantes en las lógicas conservadoras, funcionalistas y positivistas. Se cuestiona la constitución de la industria científica, el encuadramiento de la ciencia en padrones empresariales, y la prefiguración capitalista de la sociedad de las redes. Se muestra las implicaciones geopolíticas y científicas de la emergencia de

6 Publicada primero en Paris, 2001, por Editions La Découverte, en Brasil por la Loyola, São Paulo, 2002. 
las máquinas de la informática, y los cambios profundos que eso supone en la logística del pensamiento. La vertiente Mattelart aborda, analiza, critica, reflexiona en esa obra sobre las implicaciones dinamizadas por la transformación del mundo, generada por las invenciones libres y por la tecnociencia industrializada. Para ampliar sus argumentos, problematiza los escenarios postindustriales, en especial el cuadro geopolítico de la era global; discute la metamorfosis de las políticas públicas, y las consecuencias de la instauración de modelos de desreglamentación neoliberal en los Estados. Reiteradamente, critica la pretensión imperial de un mundo unipolar, la ilusión de un capitalismo sin fricción, y presenta la potencia histórica de lo que concibe como un archipiélago de las resistencias.

La problemática de la mundialización de la comunicación $n^{7}$, va a ser trabajada en la misma línea epistemológica de los libros publicados en los años 1990, época en la cual la vertiente Mattelart configuró un conjunto histórico de investigaciones importante, para el conocimiento sobre la constitución, instauración, funcionamiento, penetración de las estrategias globalitarias hegemónicas; así configuró un conjunto teórico valioso en sentido filosófico, geopolítico y económico sobre el complejo Comunicación Mundo.

Una mirada retrospectiva permite constatar que, ya en los años 1980, Armand Mattelart en colaboración con Héctor Schmucler investigaron y pensaron sobre la problemática que denominarían: América Latina en la encrucijada telemática ${ }^{8}$, en esa obra formularon una crítica profunda y sistemática al proceso de privatización del consenso, a las nuevas reglas económicas neoliberales, y a las estrategias transnacionales de informatización del mundo. Problematizaron, también, sobre la institucionalización de la informatización en los Estados, que en la nueva configuración neocolonial, se caracterizaban por estar

7 La Mondialisation de la communication, Paris, Presses Universitaires de France, 1996; la edición española fue por la Paidós Ibérica, Barcelona, 1998; y la brasileña, cambió el título para A globalização da comunicação, publicada pela EDUSC, São Paulo, 2000.

8 Armand Mattelart \& Héctor Schmucler. América Latina en la encrucijada telemática. Barcelona: Paidos, 1983. 
desequilibrados, enmascarados, espiados e integrados a la dependencia económica, política y militar estadunidense.

La vertiente Mattelart va a dar continuidad a su producción epistemológica histórica en comunicación, al abordar los procesos sistémicos de informatización, control y comunicación mundial con la obra Un mundo vigilado ${ }^{9}$; esa investigación estructura argumentaciones políticas, históricas y arqueológicas sobre la constitución de las sociedades informatizadas y mediatizadas del siglo XXI. En la primera parte, que trata de lo disciplinar/gerencial, muestra como la gestión de las sociedades contemporáneas tiene una trayectoria de institucionalización de sistemas de disciplina y de vigilancia, que están combinados con sistemas de producción de propaganda, publicidad e información para administrar el consenso y el consumo. En ese foco, se analiza la confluencia de diseños "científicos" en la biología, en la medicina, en la física, en la estadística, en la geopolítica y en la economía política, para establecer la disciplinarización y el gerenciamiento de las “masas". En la segunda parte, que trata sobre hegemonizar/pacificar, se concentra en la problematización de las realizaciones del Complejo industrial/informacional/ militar, como sistema/de/sistemas que ha conseguido establecer un poder mundial hegemónico avasallador. Para ilustrar ese proceso se presenta y analizar los casos de Argel, Chile, Irak y las estrategias de control militar en América Latina.

En la tercera parte de la investigación Un mundo vigilado aborda securizar/ insecurizar, problematiza la configuración sistémica instaurada en el siglo XXI, en la cual se produce un nuevo orden interior mediante la acción de las máquinas de vigilancia (cámaras en los espacios públicos urbanos y en las carreteras; sistemas de espionaje generalizados (PRINTS, ECHELON etc.), que producen informaciones y fichas digitales del conjunto de la población; y, también, construyen y operacionalizan dispositivos de observación, registro y control de la ciudadanía, mediante aplicativos instalados en los microcomputadores

9 Armand Mattelart. Un mundo vigilado. Barcelona: Paidós, 2009; publicado en francés em 2007, por la Découverte con el título La globalisation de la surveillance. Aux origens de l'odre sécuritarie. 
y en los nanocomputadores. Esta investigación muestra, también, la combinación de estrategias político/militares a nivel mundial, como la USA Patriot Act, que ha permitido internacionalizar la tortura, la impunidad, el secuestro, el asesinato de ciudadanos de todos los continentes por el terrorismo de Estado de los EUA. En esa línea, la investigación demuestra fehacientemente, como el gobierno de los EUA quiebra las normas internacionales jurídicas, diseña su Abogacía de Guerra (Lawfare), para derrocar gobiernos, destruir movimientos sociales y políticos, e imponer condiciones ventajosas a los intereses económicos, militares y políticos del imperio. En esa perspectiva es sintomática la "autocensura editorial" en Brasil, que mediante lógicas de mercadeo justifica el desinterés en publicar obras de relevancia como Un mundo vigilado y De Orwell al Cibercontrol ${ }^{10}$, que profundizan en la problemática del control, de la vigilancia, de la gestión del espionaje generalizado, del diseño de los boicots y de los Golpes de Estado informáticos (con singular continuidad en la segunda década del siglo XXI en América Latina). Se evita publicar también esas investigaciones por su contribución estratégica a la crítica de la gestión de la fuerza de trabajo, hiper/explotada en los formatos digitalizados; así se evita dar a conocer sobre la explotación mercantil de los datos de las personas comunes, y se deja que la fiebre de la retórica sobre la seguridad y el cibercontrol (invisible y móvil) penetre y sea naturalizada por los ciudadanos como un factor de provecho para su vida social. Las investigaciones y sistematizaciones de la vertiente Mattelart ofrecen informaciones estratégicas, cruciales para el conocimiento de los ciudadanos del mundo; esas obras, lamentablemente, ni siquiera en la comunidad académica de comunicación han sido suficientemente trabajadas con rigor y profundidad.

Las contribuciones teóricas y epistemológicas de la vertiente Mattelart para la problemática de la Cultura han sido singularmente valiosas; es así como, ya en los años 1960-70 investigaban y problematizaban

10 Armand Mattelart \& André Vitalis. De Orwell al cibercontrol. Gedisa : Barcelona: 2015; en francés Le profilage des populations. Paris : Editions La Découverte, 2014. 
los géneros y las estrategias mediáticas de amplia penetración en los sectores populares, y en la gran mayoría de los públicos. La vertiente Mattelart fue pionera en América Latina al asumir como problemas/ objeto relevantes para la investigación científica los comics ${ }^{11}$, las fotonovelas, las telenovelas ${ }^{12}$, las series radiofónicas y televisivas, la información periodística ${ }^{13}$. De esa manera fueron constituyendo una vertiente epistemológica comunicacional histórica crítica sobre la realidad latinoamericana y mundial; ese compromiso, y esa excelencia investigativa hizo que trabajasen la categoría Cultura en términos de Frentes Culturales ${ }^{14}$, de geopolíticas ${ }^{15}$, de crítica de los medios $^{16}$, de diversidades $^{17}$, estudios culturales ${ }^{18}$, de publicidad ${ }^{19}$, de tecnología ${ }^{20}$.

Michèle Mattelart ha sido una pensadora y una investigadora estratégica de las problemáticas comunicacionales trabajadas por la vertiente, tanto en Pensar sobre los medios cuanto en Historia de las teorías de la comunicación su participación epistemológica fortalece y amplia la comprensión sobre nuestro campo de conocimiento y de trabajo. Las investigaciones sobre fotonovelas y telenovelas ganaron con $\mathrm{su}$ pensamiento y acción investigativa en sensibilidades, reflexiones, miradas y visualizaciones profundas y diversas. En la dimensión política la obra de Michèle Comunicación e ideologías de la seguridad ${ }^{21}$ muestra la claridad y consistencia crítica de su pensamiento a respecto de los poderes hegemónicos vigentes en América Latina y en el mundo.

11 Ariel Dorfman \& Armand Mattelart. Para leer al Pato Donald: comunicación de masas y colonialismo. Santiago: Siglo XXI, 1972.

12 Mattelart, A. \& Mattelart, M. (1989). O carnaval das imagens a ficção na TV. São Paulo: Brasiliense.

13 Mattelart, A. \& Mattelart, M. (1976). Los medios de comunicación de masas: la ideología de la prensa liberal en Chile, Buenos Aires: El Cid Editor.

14 Mattelart, A. \& Mattelart, M. (1977). Frentes Culturales y Movilización de masas. Barcelona: Anagrama.

15 Mattelart, A. (1993). Geopolítica de la cultura. Santiago/Montevideo: LOM/TRILCE.

16 Mattelart, A. \& Mattelart, M. (1987). A cultura contra a democracia? O audiovisual na época transnacional. São Paulo: Brasiliense.

17 Mattelart, A. \& Piemme, J. M. (1981). La televisión alternativa. Barcelona: Anagrama. Mattelart, A. (2005). Diversidade cultural e mundialização. São Paulo: Parábola.

18 Mattelart, A. \& Neveu, É. (2004). Introdução aos estudos culturais. São Paulo: Parábola.

19 Mattelart, A (1991). La publicidad. Barcelona: Paidós, 1991. (Edición francesa La Découverte, 1990).

20 Mattelart, A. \& Stourdze, Y. (1984). Tecnología, cultura y comunicación, Barcelona: Mitre.

21 Mattelart, M. (1978). Comunicación e ideologías de la seguridad. Barcelona: Anagrama. 
En su vasta e importante producción, Michèle Mattelart ha investigado las problemáticas de género, relacionadas con las estructuraciones y configuraciones culturales predominantes; son representativas, en ese aspecto, sus obras La cultura de la opresión femenina ${ }^{22}$ y Mujeres e industrias culturales ${ }^{23}$.

Antes de eso, ya en finales de los años 1960, en su primer estudio: La mujer chilena en la nueva sociedad, mostró su fortaleza teórica crítica al analizar el modelo de control de la natalidad estadounidense, que se aprovechaba de los símbolos femeninos mediáticos para influir en los comportamientos de las mujeres latinoamericanas; en esa investigación, la crítica al modelo difusionista es esclarecedora y potente. En las obras referidas Michèle Mattelart va a producir una crítica al papel de la mujer en las sociedades patriarcales de opresión; su mirada afinada sobre lo cotidiano, como temporalidad social crucial, y su deconstrucción de las estrategias mediáticas (fotonovelas, revistas femeninas, telenovelas, series, programas sobre la mujer) han sido paradigmáticas para la investigación crítica en comunicación. La valorización por Michèle de la investigación que problematiza la programación mediática concreta, aquella que reproduce los esquemas, los hábitos, las naturalizaciones y los poderes de los sistemas de opresión femenina, ha orientado e instituido líneas de investigación fecundas en el campo.

Así Michèle Mattelart ha construido argumentos transdisciplinares, crítico dialécticos y transmetodológicos, que combinan visualizaciones históricas cruciales sobre la lucha de la mujer por la emancipación y la liberación; para eso, ha articulado aspectos clasistas, mediáticos, territoriales, económico-políticos, de género, de poderes transnacionales, y de alternativas de resistencia y de cambio, en profunda interrelación con la transformación integral del mundo.

La vertiente Mattelart se ha nutrido de valiosas compañías y colaboraciones mediante la organización de colectivos, centros, revistas, asesorías y misiones internacionales, que han hecho posible

22 Mattelart, M. (1977). La cultura de la opresión femenina. México: Era.

Mattelart, M. (1982). Mujeres e industrias culturales. Barcelona: Anagrama. 
un trabajo epistemológico, teórico y metodológico fructífero, y de significativa participación en los procesos históricos latinoamericanos y mundiales. Las cooperaciones solidarias con los países en situación de marginalización, de ataque, de bloqueo, de pobreza e necesidad, han contribuido con el fortalecimiento de mejores condiciones de producción educativa, comunicativa, política y cultural. Los premios, reconocimientos, doctorados honoris causa, profesores eméritos etc., en nivel internacional, expresan, en parte, la potencia de esa vertiente, que ha brindado un conjunto fecundo de investigaciones, de teorías y de visualizaciones epistemológicas, necesarias para la continuidad del fortalecimiento del campo de conocimiento en comunicación, y, principalmente, para la imprescindible transformación del mundo en perspectiva ecológica, digna, justa y libertaria.

\section{Referencias}

Mattelart A. \& Mattelart, M. (1976). Los medios de comunicación de masas: la ideología de la prensa liberal en Chile, Buenos Aires: El Cid Editor.

Mattelart, A. (1976). Multinacionales y sistemas de comunicación. Barcelona: Anthropos.

Mattelart, M. (1977). La cultura de la opresión femenina. México: Era.

Mattelart, A. \& Mattelart, M. (1977). Frentes Culturales y Movilización de masas. Barcelona: Anagrama.

Mattelart, M. (1978). Comunicación e ideologías de la seguridad. Barcelona: Anagrama

Mattelart, A. \& Piemme, J. M. (1981). La televisión alternativa. Barcelona: Anagrama.

Mattelart, M. (1982). Mujeres e industrias culturales. Barcelona: Anagrama.

Mattelart, A. \& Sshmucler, H. (1983). América Latina en la encrucijada telemática. Buenos Aires: Paidós.

Mattelart, A. \& Stourdze, Y. (1984). Tecnología, cultura y comunicación, Barcelona: Mitre. 
Mattelart, A. \& Mattelart, M. (1987). Pensar sobre los medios: comunicación y crítica social. Madrid: FUNDESCO.

Mattelart, A. \& Mattelart, M. (1987). A cultura contra a democracia? O audiovisual na época transnacional. São Paulo: Brasiliense.

Mattelart, A. \& Mattelart, M. (1989). O carnaval das imagens a ficção na TV. São Paulo: Brasiliense.

Mattelart, A. (1993). Geopolítica de la cultura. Santiago/Montevideo: LOM/TRILCE.

Mattelart, A (1991). La publicidad. Barcelona: Paidós, 1991. (Edición francesa La Découverte, 1990).

Mattelart, A (1994). Comunicação mundo: história das ideias e das estratégias. Petrópolis/RJ: Vozes.

Mattelart, A (1996). A invenção da comunicação. Lisboa: Instituto Piaget.

Mattelart, A. \& Mattelart, M. (1997). Historia de las teorías de la comunicación. Barcelona: Paidós.

Mattelart, A (1998). La mundialización de la comunicación. Buenos Aires: Paidós. Mattelart, A (2000). A globalização da comunicação. Bauru/SP: EDUSC.

Mattelart, A (2002). História da sociedade da informação. São Paulo: Loyola.

Mattelart, A (2002). História da utopia planetária: da cidade profética à sociedade global. Porto Alegre: Sulina.

Mattelart, A. \& NEVEU, É. (2004). Introdução aos estudos culturais. São Paulo: Parábola.

Mattelart, A. (2005). Diversidade cultural e mundialização. São Paulo: Parábola. Mattelart, A. (2009). Un mundo vigilado. Barcelona: Paidós.

Mattelart, A.\& Sénecál, M. (2014). Por una mirada mundo Armand Mattelart: un recorrido por la trayectoria de uno de los grandes teóricos de la comunicación y de la cultura (conversaciones con Michel Sénécal).

Mattelart A. \& Vitalis, A. (2015). De Orwell al cibercontrol. Barcelona; Gedisa. 
